\title{
Um estudo comparativo do desempenho econômico-financeiro em BR GAAP, US GAAP e IFRS na Gerdau S.A.
}

\section{(A comparative study of the economic-financial performance in BR GAAP, US GAAP and IFRS in Gerdau S.A.)}

\author{
Jaluza Maria Lima Silva Borsato \\ Daiana Paula Pimenta \\ Kárem Cristina de Sousa Ribeiro
}

\begin{abstract}
Resumo
O crescimento da economia global e a maior integração dos mercados mundiais trouxeram a necessidade de adoção de padrões contábeis unificados, cujo principal objetivo é proporcionar critérios de comparabilidade e transparência entre empresas de diferentes países, buscando disponibilizar informações financeiras de melhor qualidade para acionistas e autoridades responsáveis. Nesse contexto, este estudo objetiva comparar os dados evidenciados segundo as normas contábeis brasileiras, americanas e internacionais, apoiando-se em uma análise de indicadores econômico-financeiros calculados a partir das demonstrações financeiras preparadas com base nessas diferentes normas. Como metodologia realizou-se um estudo de caso. Como resultados a pesquisa apontou que as informações sobre o desempenho econômico-financeiro e geração de valor, quando se consideram as demonstrações em Brasilian Generally Accepted Accounting Principles (BR GAAP), United States Generally Accepted Accounting Principles (US GAAP) e International Financial Reporting Standards (IFRS), apresentaram resultados diferenciados para uma mesma organização, dependendo do padrão contábil adotado.
\end{abstract}

Palavras-chave: Desempenho econômico-financeiro; Normas contábeis; Gerdau S/A.

\begin{abstract}
The growth of global economy and the greater integration of global markets have brought about the need to adopt unified accounting standards whose main objective is to provide comparability and transparency for between companies from different countries, so as to make higher quality financial information available to shareholders and authorities. In that context, this study aims to compare data obtained from Brazilian, American and international accounting standards, based on an analysis of economic-financial indicators calculated from financial statements prepared according to those different norms. The methodology was that of case study. Results indicated that the information on economic-financial performance and creation of value, considering statements in Brazilian Generally Accepted Accounting Principles (BR GAAP), United States Generally Accepted Accounting Principles (US GAAP) and International financial Reporting Standards (IFRS), was different for the same organization, depending on the adopted countable standard.
\end{abstract}

Key words: Economic-financial performance; Accounting norms; Gerdau S/A.

O desenvolvimento econômico, a abertura dos mercados e a evolução dos mercados de capitais pelo mundo provocaram mudanças na estrutura das organizações. Há muito se vem 
observando a consolidação de processos importantes, como a maior interdependência entre as nações, trazendo consigo a intensificação da concorrência e o maior impacto e difusão da evolução tecnológica na sociedade. Os novos tempos ensejam quebra de paradigmas amplamente difundidos e aceitos.

Nesse contexto, as novas regras contábeis impostas pela lei 11.638/07 promoverão uma inserção ainda maior do país nos mercados globais de capitais, na medida em que possibilitarão que as empresas brasileiras de capital aberto preparem suas demonstrações financeiras exclusivamente em International Financial Reporting Standards (IFRS), padrões atualmente adotados nos principais mercados de valores mobiliários. Tais mudanças certamente contribuirão para o fortalecimento do mercado de capitais do Brasil.

O principal objetivo dessa nova lei, que entrou em vigor em $1^{\circ}$ de janeiro de 2008 , foi atualizar as regras contábeis brasileiras e aprofundar a harmonização dessas regras com os pronunciamentos internacionais, em especial os emitidos pelo International Accounting Standards Board (IASB), por meio das IFRS. Essa harmonização, a partir do acordo do Financial Accounting Standards Board (FASB) X IASB cunhado como convergência, parece irreversível e insere-se no contexto do aprimoramento das práticas de governança corporativa das empresas, e consequentemente contribui para melhorar a divulgação de informações e aumentar a exposição aos investidores internacionais e ao mercado em geral.

Entretanto, o uso de diferentes normas, como BR GAAP (Brasilian Generally Accepted Accounting Principles), US GAAP (United States Generally Accepted Accounting Principles) e IFRS para a elaboração das demonstrações financeiras, pode acarretar resultados distintos quando se analisa uma empresa. Bernardi, Costa e Ikeda (2002) afirmam que, como resultado, seria possível obter informações contábeis diferenciadas para uma mesma organização, dependendo do padrão contábil empregado.

Nesse contexto, a questão-problema que orienta esta pesquisa é: Existem diferenças significativas nos valores dos indicadores econômico-financeiros e na geração de valor para a empresa quando estes são calculados a partir de demonstrações financeiras elaboradas em BR GAAP, US GAAP e IRFS?

Para responder à questão-problema, este estudo objetiva comparar os dados evidenciados segundo as normas contábeis brasileiras, americanas e internacionais, apoiado em uma análise de indicadores de desempenho e de geração de valor calculados a partir das demonstrações financeiras preparadas com base nessas diferentes normas pela empresa Gerdau S.A. 
O estudo justifica-se por abordar possíveis divergências nas informações geradas pelas demonstrações financeiras e a escolha da empresa, por divulgar seus relatórios nas diferentes normas.

$\mathrm{O}$ artigo está estruturado em cinco seções, iniciando com a introdução do estudo. Na sequência faz uma incursão teórica nos indicadores de desempenho, na gestão baseada em valor, nas medidas de criação de valor e na harmonização das normas contábeis internacionais. A terceira seção apresenta o método e os procedimentos da pesquisa. Em seguida, apresenta os resultados da pesquisa, destacando as diferenças entre os indicadores de desempenho e de valor calculados com base nas demonstrações financeiras preparadas de acordo com as normas contábeis brasileiras, americanas e internacionais. Por último apresenta as conclusões da pesquisa realizada.

\section{Fundamentação teórica}

\section{Análise das demonstrações financeiras e principais indicadores de desempenho}

As demonstrações financeiras são o conjunto de informações que devem ser obrigatoriamente e periodicamente divulgadas, e as que têm ciclo operacional maior que um ano, segundo a Lei 6.404/76, pela administração de uma sociedade por ações e representam a sua prestação de contas para os sócios e acionistas, e de maneira geral para a sociedade. Essa prestação anual de contas é composta pelo relatório da administração, as demonstrações contábeis e as notas explicativas que as acompanham, o parecer dos auditores independentes e o parecer do conselho fiscal.

A Lei 11.638/07, que alterou a Lei 6.404/76, definiu e estendeu às sociedades de grande porte disposições relativas à elaboração e publicação de demonstrações contábeis nela disciplinadas. Essa lei dispõe sobre os requisitos de qualificação de entidades de estudo e divulgação de princípios, normas e padrões de contabilidade e auditoria, como organizações da sociedade civil de interesse público.

Segundo Reis (2003), somente pelo entendimento da estrutura contábil das demonstrações é que se pode desenvolver avaliações mais detalhadas das empresas. Mais especificamente, todo processo de análise requer conhecimentos sólidos da forma de contabilização e apuração das demonstrações, sem os quais ficam seriamente limitadas as conclusões extraídas sobre o desempenho da empresa.

A análise das demonstrações financeiras constitui uma ferramenta fundamental na geração de informações sobre o desempenho, a situação econômico-financeira e a gerência das empresas. Essas demonstrações são fundamentais para a elaboração do diagnóstico financeiro 

NETO, 2007).

Segundo Linhares (2003), a análise dessas demonstrações propicia a avaliação do patrimônio da empresa. Como fonte de elaboração de relatórios gerenciais, avalia o resultado econômico e financeiro da organização em um momento estático ou não, em diversos períodos, apresentando-se como uma determinante na comparação entre os resultados realizados e os planejados, servindo de suporte para ações que melhorem seu desempenho no futuro.

Para Marion (2006), Assaf Neto (2007) e Matarazzo (2007), as técnicas mais comuns de análise baseiam-se na apuração de indicadores econômico-financeiros, os quais podem ser subdivididos em quatro grupos: índice de liquidez, atividade, endividamento e estrutura e rentabilidade.

Para este trabalho serão considerados os indicadores de liquidez, endividamento e estrutura e rentabilidade, propostos por Assaf Neto (2007). Segundo esse autor, os indicadores de liquidez evidenciam a situação financeira de uma empresa frente a seus diversos compromissos financeiros. Os indicadores de endividamento e estrutura avaliam a proporção de recursos próprios e de terceiros mantidos pela empresa, a dependência financeira por dívidas de curto prazo, a natureza de suas exigibilidades e o risco financeiro. Já os indicadores de rentabilidade representam uma avaliação econômica do desempenho da empresa, dimensionando o retorno sobre os investimentos realizados e a lucratividade apresentada pelas vendas.

Outros indicadores poderiam ser utilizados neste trabalho, mas os destacados acima foram escolhidos em razão dos dados requisitados para seus cálculos estarem disponíveis nas demonstrações financeiras publicadas pela empresa pesquisada.

\section{Gestão baseada em valor e medidas de criação de valor}

Conforme Assaf Neto (2007), a gestão das empresas vem revelando importantes avanços em sua forma de atuação, saindo de uma postura convencional de busca do lucro e rentabilidade para um enfoque preferencialmente voltado à riqueza dos acionistas.

O aumento da importância dos acionistas na maioria dos países desenvolvidos levou um número crescente de administradores a concentrar-se na criação de valor como a medida mais importante do desempenho corporativo (COPELAND; KOLLER; MURRIN, 2002).

O objetivo de criar valor aos acionistas demanda estratégias financeiras e medidas do sucesso empresarial. Criar valor para uma empresa ultrapassa o objetivo de cobrir os custos explícitos identificados nas vendas. Esse processo incorpora a remuneração dos custos implícitos, custo de oportunidade do capital investido, não cotejado pela contabilidade 
tradicional na apuração dos demonstrativos de resultados, e consequentemente a quantificação da riqueza dos acionistas (ASSAF NETO, 2007).

A Value-Based Management (VBM - Gestão Baseada em Valor) é uma abordagem que envolve a gestão da empresa como um todo, e que leva os gestores a repensar os processos de gerenciamento, o que vai desde o desenvolvimento de estratégias até a definição de indicadores de desempenho, considerando a maximização do valor como meta financeira da empresa (COPELAND; KOLLER; MURRIN, 2000).

Na Figura 1 apresenta-se a visão sintética de uma VBM segundo Assaf Neto (2003):

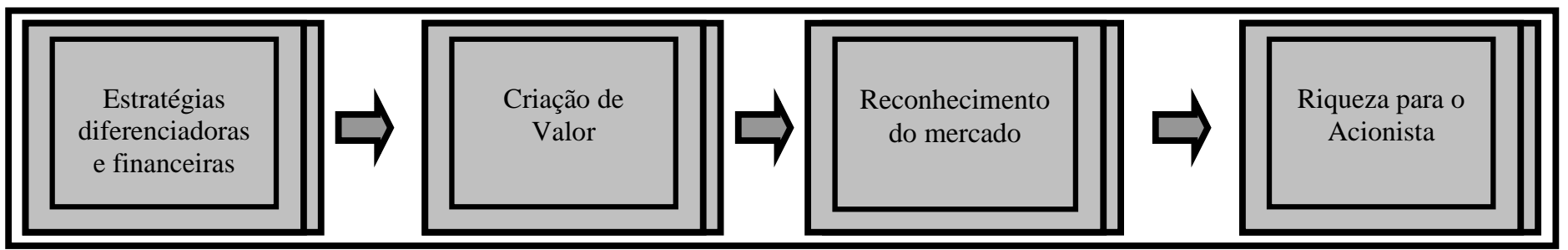

Figura 1 - Visão sintética de uma VBM.

Fonte: Adaptado de Assaf Neto (2003).

Segundo Assaf Neto (2007), a empresa define estratégias de diferenciação, que irão agregar vantagem competitiva ao negócio, e estratégias financeiras, para criar valor para o acionista. Então, para cada estratégia são definidos objetivos e para cada objetivo, direcionadores de valor capazes de conduzir a empresa à geração de riqueza.

Um dos direcionadores de valor mais usados é o EVA (Economic Value Added). Araújo (2002) conceitua o EVA como uma medida de desempenho econômico que representa a estrutura para um sistema completo de gerência financeira e remuneração variável, que pode auxiliar o processo de tomada de decisões das empresas.

Para Assaf Neto (2007), o EVA pode ser entendido como o resultado apurado pela sociedade que excede à remuneração mínima exigida pelos proprietários de capital, podendo ser estes credores e/ou acionistas. É um indicador que evidencia se a empresa está criando ou destruindo valor através de um resultado definido como supranormal por David Ricardo no início do século passado.

Se uma empresa for capaz de remunerar seus proprietários somente até o limite de suas expectativas mínimas de retorno, o seu valor de mercado restringe-se ao montante necessário que despenderia para edificá-la, ou seja, ao valor de reposição de seus ativos. O valor é criado ao acionista somente quando as receitas de vendas superarem todos os dispêndios incorridos. Assim, o valor da empresa excederia ao de realização de seus ativos, indicando esse resultado 

ou goodwill (ASSAF NETO, 2007).

O MVA é utilizado como uma medida de avaliação do valor econômico, refletindo o sucesso da empresa em suas decisões financeiras. A maximização da riqueza agregada é o objetivo principal de qualquer empresa com relação ao bem-estar econômico de seus acionistas (ASSAF NETO, 2007, p. 261).

\section{Harmonização das normas contábeis internacionais}

O crescimento da economia global e a maior integração dos mercados mundiais trouxeram a necessidade de adoção de padrões contábeis unificados, cujo principal objetivo é proporcionar critérios de comparabilidade e transparência entre empresas de diferentes países, buscando disponibilizar informações financeiras de melhor qualidade para acionistas e autoridades responsáveis. Diante disso, a contabilidade tem função importante nessa relação, pois "a informação é uma das maneiras de reduzir a incerteza, dando aos contadores papel importante na divisão de riscos entre administradores e proprietários" (HENDRIKSEN; VAN BREDA, 1999, p. 139).

A evidenciação e a harmonização das normas contábeis vêm sendo objeto de vários estudos nos últimos anos. A padronização e harmonização diferem essencialmente por sua finalidade: a primeira busca uniformizar e a segunda aproximar. A padronização tem o objetivo de tornar obrigatória a adoção de padrões contábeis iguais para todas as empresas de todos os países. A harmonização implica a disponibilização de métodos contábeis alternativos, dependendo das características próprias da empresa e do ambiente onde ela atue. A empresa, nesse caso, utilizaria o modelo mais adequado para a sua situação, sem obstáculos da legislação nacional (WEFFORT, 2005).

As normas contábeis utilizadas em países da União Europeia, Estados Unidos e Brasil podem ser descritas conforme quadro a seguir:

Quadro 1

Normas contábeis internacionais, americanas e brasileiras

\begin{tabular}{c|l}
\hline Normas & \multicolumn{1}{c}{ Descrição } \\
\hline \multirow{3}{*}{ IFRS } & Normas internacionais de contabilidade elaboradas pelo IASB, entidade sem fins \\
& lucrativos sediada em Londres, criada em $1^{\circ}$ de abril de 2001 para promover ajustes \\
& nas normas contábeis internacionais elaboradas pelo seu precedente, o International \\
& Accounting Standards Committee (IASC), denominadas de IAS (International \\
& Accounting Standard), hoje responsável pela padronização das normas contábeis, \\
& utilizadas também como padrão contábil pela União Europeia e por vários países. \\
\hline & $\begin{array}{l}\text { Normas contábeis aceitas nos Estados Unidos, elaboradas pelo FASB, organização } \\
\text { designada para estabelecer os padrões de contabilidade financeira e de elaboração } \\
\text { das demonstrações financeiras para as empresas do setor privado dos Estados }\end{array}$ \\
\hline
\end{tabular}


US GAAP $\quad$ Unidos. A edição de normas pelo FASB para a elaboração das demonstrações financeiras é autorizada e reconhecida oficialmente pelo Securities and Exchange Commission (SEC), organismo do governo americano responsável pela proteção dos investidores e manutenção da integridade do mercado. Essas normas são consideradas pelo SEC como essenciais para o eficiente funcionamento da economia, porque os investidores, credores, auditores e outras partes interessadas necessitam que as informações financeiras possuam credibilidade, transparência e comparabilidade.

BR GAAP Normas contábeis brasileiras regidas pela Lei $\mathrm{n}^{\circ}$ 6.404/76, que dispõe sobre as sociedades por ações. Os resultados apurados na elaboração das demonstrações financeiras são função também dos critérios definidos pela Lei $n^{\circ} 9.430$, de 27 de dezembro de 1996, que dispõe sobre a legislação tributária federal, e pelo regulamento do imposto de renda, Decreto $\mathrm{n}^{\circ} 3.000$, de 26 de março de 1999.

Fonte: Adaptado da Revista KPMG (2008).

O processo de convergência ganhou impulso mundial a partir de $1^{\circ}$ de janeiro de 2005 , data oficial da implementação das normas contábeis internacionais das companhias listadas na União Europeia. Outros países como China, Rússia, África do Sul e Austrália têm implementado programas de convergência entre suas normas locais e as IFRS. No Brasil esse processo de convergência foi iniciado pela CVM (Comissão de Valores Mobiliários), órgão regulador do mercado de capitais do país, o qual emitiu normas que aprovaram alguns pronunciamentos alinhados aos padrões internacionais. E a instrução CVM no 457, editada em julho de 2007, alinhada ao comunicado do Banco Central, determinou que as companhias brasileiras de capital aberto passem a elaborar demonstrações financeiras consolidadas, com base nas IFRS, a partir do exercício de 2010 (KPMG, 2008).

Ricci (2003) destaca que, “devido ao uso de diferentes padrões, pode-se incorrer no fato de se obter resultados distintos quando se analisa uma entidade, dados ou diversos entendimentos de uma linguagem contábil para outra”. Em relação a isso, Bernardi, Costa e Ikeda (2002) comentam que, "como resultado, seria possível obter informações contábeis diferenciadas para uma mesma organização, dependendo do padrão contábil empregado naquela região".

\section{Divergências nas normas contábeis em âmbito internacional}

Os estudos sobre as diferenças das normas contábeis internacionais apontam quase todos na mesma direção, atribuindo-as às características e ao sistema legal de cada país.

O Quadro 2 mostra as principais diferenças entre o preconizado pelo IASB, o FASB e as normas brasileiras de contabilidade para o reconhecimento e mensuração de variações patrimoniais.

Quadro 2

Principais diferenças entre as IFRS, US GAAP e normas brasileiras de contabilidade. 
Divergências

Gastos com pesquisa e desenvolvimento

Contabilização do leasing financeiro

IASB - geralmente reconhecidos como despesa do período. Ativados somente em casos específicos.

FASB - todos os gastos com pesquisa e desenvolvimento devem ser levados a resultado de maneira imediata, sem exceções.

BRASIL - devem ser capitalizados como ativo e amortizados durante o período esperado de futuros benefícios econômicos, não superior a dez anos. IASB - é admitida para alguns ativos específicos. O IAS 16 aceita a reavaliação como tratamento alternativo, para evitar a divergência material entre o custo e o respectivo valor econômico de mercado.

\begin{tabular}{l|l} 
Reavaliação de ativos & FASB - pró́be qualquer tipo de reavaliação.
\end{tabular}

BR GAAP - Eliminação da reserva de reavaliação: eliminada a possibilidade de reavaliação espontânea. A critério das Cias. o saldo dessa reserva ora existente pode ser mantido ou estornado. Nesse último caso, o estorno deve ser feito até o final do exercício de 2008.

IASB - a essência deve prevalecer sobre a forma. $\mathrm{O}$ bem deve ser registrado pela arrendatária como ativo imobilizado em contrapartida a uma obrigação no passivo.

FASB - segue a mesma linha do IASB, mas possui critérios definidos para caracterizar um leasing como financeiro. Nesse caso, o contrato deve ter pelo menos um desses requisitos: transferência de propriedade do bem para a arrendatária, valor de compra a preço de barganha, o prazo contratual deve ser superior a $75 \%$ da vida útil econômica do bem ou o valor presente dos pagamentos mínimos do leasing deve ser superior a $90 \%$ do valor de mercado do bem arrendado na data de início da operação.

BRASIL - são contabilizados como aluguel em obediência à legislação fiscal, tanto na arrendatária como na arrendadora, embora o CFC adote os mesmos parâmetros do IASB.

IASB - o goodwill adquirido deve ser capitalizado como ativo e amortizado durante o prazo de vida útil, não superior a 20 anos. Caso se queira adotar um prazo superior a esse, deve ser realizado anualmente o teste de

Contabilização do goodwill impairment. O goodwill gerado internamente não pode ser capitalizado.

FASB - deve ser capitalizado no ativo e realizado anualmente o teste de impairment, levando-se a resultado a diferença entre o valor do goodwill apurado e o efetivamente capitalizado.

BRASIL - tratado como ágio, deve ser ativado e amortizado de acordo com a vida útil, não superior a dez anos. A legislação fiscal permite a inclusão do goodwill como um ativo, que deve ser amortizado em até cinco anos.

IASB - contabilização pelo regime de competência, com reconhecimento de

Encargos com planos de benefícios de aposentadoria para empregados

Instrumentos financeiros um passivo atuarial e de um ativo financeiro avaliado por fair value (IAS 19).

FASB - similares às normas do IASB.

BRASIL - observa em essência o IAS 19, a partir de 2001, mas somente para as companhias abertas autorizadas pela CVM (Deliberação 31/00). As demais adotam o regime de caixa.

IASB - os derivativos devem ser registrados como itens do balanço patrimonial, como ativos e passivos pelo fair value (valor justo) e, usualmente, ajustes ao fair value devem ser reconhecidos como resultado, quando incorridos, exceto aqueles derivativos classificados como hedge (IAS 39).

FASB - normas idênticas ao IASB (SFAS 133)

BRASIL - somente as instituições financeiras subordinadas ao controle e fiscalização do Banco Central adotam regras contábeis internacionais. As companhias abertas estão sujeitas apenas à evidenciação em notas explicativas dos valores de mercado - para opções, futuros, a termo e swaps. As demais sociedades anônimas, subordinadas à Lei $n^{\circ} 6.404 / 6$, não estão obrigadas a qualquer tipo de divulgação desses instrumentos.

IFRS - não definem um formato específico, mas requerem segregação entre ativos e passivos correntes e não-correntes. A apresentação por ordem de liquidez somente é preferível quando apresentar informação mais confiável. 
Fonte: adaptado de Niyama (2005, p. 55-83), PricewaterhouseCoopers (2006, p.12-25), Lei 11.638/0.

Para Klann, Beuren e Hein (2007), essas divergências podem impactar valores constantes das demonstrações financeiras. Uma mesma empresa pode apresentar diferentes composições de ativos e passivos e resultados divergentes, ao se analisar suas demonstrações financeiras enviadas para diferentes países ou mercados. Essas diferenças acabam por alterar o valor dos indicadores de desempenho, calculados a partir dessas demonstrações.

\section{Metodologia}

Através de uma análise criteriosa dos diferentes tipos de pesquisa, identifica-se como a mais adequada para o desenvolvimento do presente trabalho o uso de um estudo descritivo. Justifica-se a utilização desse instrumento pelo fato de o objetivo do estudo estar bem definido, os pesquisadores saberem exatamente o que pretendem com a pesquisa, como buscar as informações e como verificar sua frequência.

A abordagem predominante deste estudo estabeleceu-se segundo as premissas da pesquisa qualitativa, privilegiando-se a revisão e a seleção da bibliografia, bem como a análise de documentos que se relacionavam ao problema, ao tema e aos assuntos correlatos.

Os relatórios financeiros anuais estudados englobaram os seguintes documentos: balanço patrimonial, demonstração do resultado do exercício, notas explicativas às demonstrações contábeis, relatório da administração e parecer dos auditores independentes.

Foram utilizadas, neste trabalho, as demonstrações financeiras consolidadas e padronizadas submetidas à Comissão de Valores Mobiliários (CVM), à NYSE e ao relatório $20 \mathrm{~F}$ da SEC, referentes ao exercício de 2006. O acesso aos relatórios foi por meio de uma consulta na home page da empresa.

A análise dos dados foi baseada na teoria de finanças. Para cada norma contábil foram calculados, segundo Assaf Neto (2007), indicadores de liquidez, endividamento e estrutura e rentabilidade, escolhidos em razão de os dados requisitados para seus cálculos estarem disponíveis nas demonstrações financeiras publicadas pela empresa pesquisada.

Dentre os diversos indicadores de liquidez, para este trabalho, foram consideradas a liquidez corrente (LC) e a liquidez geral (LG), as quais evidenciam a situação financeira da 
empresa, a curto prazo (liquidez corrente) e a longo prazo (liquidez geral), e são dadas pelas seguintes equações:

$$
\begin{aligned}
& \text { LC: AC / PC (1) } \\
& \text { LG: }(A C+\text { ARLP) / (PC + PELP) (2) }
\end{aligned}
$$

Dentre os indicadores de endividamento, ou seja, os que podem ser úteis para a análise das fontes permanentes de capital utilizadas por uma empresa, consideraram-se a relação de capital de terceiros/capital próprio (CT/CP), a relação capital de terceiros/passivo total (CT/PT), a imobilização de recursos permanentes (IRP), dadas por:

$$
\begin{aligned}
& \text { CT/PL: ET (PC+PELP) / PL (3) } \\
& \text { CT/PT: ET / PT (ET+PL) (4) } \\
& \text { IRP: AP / PELP+PL (5) }
\end{aligned}
$$

Em relação aos indicadores de rentabilidade, calcularam-se o retorno sobre $\mathrm{o}$ investimento (ROI) e o retorno sobre o patrimônio líquido (ROE), os quais representam uma avaliação econômica do desempenho da empresa, dimensionando-se o retorno sobre os investimentos realizados e a lucratividade apresentada pelas vendas. As fórmulas utilizadas para o cálculo foram:

$$
\begin{aligned}
& \text { ROI: LO / AT (6) } \\
& \text { ROE: LL / PL (7) }
\end{aligned}
$$

Além dos indicadores econômico-financeiros, calcularam-se também as medidas de criação de valor, EVA e MVA. Segundo Assaf Neto (2007), o EVA pode ser calculado por meio de uma formulação analítica que evidencia em quanto o retorno dos investimentos superou as expectativas de remuneração dos proprietários de capital. O EVA é dado pela seguinte fórmula:

$$
\mathrm{EVA}=(\mathrm{ROI}-\mathrm{CMPC}) \times \mathrm{INV}(8)
$$

Onde:

O ROI representa retorno sobre o investimento formado pelo produto do giro e margem operacional; o investimento conota o total dos recursos próprios e de terceiros deliberadamente levantados pela empresa e aplicados em seu negócio e o CMPC evidencia o custo médio ponderado de capital.

A premissa dessa abordagem considera que um retorno do investimento inferior ao CMPC leva à destruição do valor de mercado da empresa. Por outro lado, se o retorno esperado 
supera esse custo, revela uma agregação de valor à empresa, o que coincide com o objetivo de maximização do valor de mercado.

O MVA é utilizado como uma medida de avaliação do valor econômico, refletindo o sucesso da empresa em suas decisões financeiras, e é dado por:

$$
\mathrm{MVA}=\mathrm{EVA} / \mathrm{CMPC}(9)
$$

Para o cálculo do CMPC, o custo do capital de terceiros (Ki) utilizado foi de 6,7\% e os dados para o cálculo do custo de capital próprio (Ke) foram obtidos na base de dados Economática. Para o cálculo do custo do capital próprio, consideraram-se os seguintes valores: Taxa livre de risco (Rf) 1,4; Coeficiente $\beta$ 1,35; Retorno da carteira de mercado (Rm) $6 \%$ e Prêmio pelo risco país ( $\alpha$ br) 1,4 .

Em BR GAAP, IFRS e US GAAP a estrutura de capital da empresa no ano de 2006 era composta, respectivamente, por $80,48 \%, 46,75 \%$ e $47,02 \%$ de capital próprio (We) e 19,52\%, $53,25 \%$ e 52,98\% de capital de terceiros (Wi). O CMPC foi calculado com base nas três normas, totalizando 8,56\% em BR GAAP, 7,78\% em IFRS e 7,79\% em US GAAP.

As fórmulas utilizadas para o cálculo do CMPC e do Ke foram as seguintes:

$$
\begin{aligned}
& \mathrm{CMPC}=(\mathrm{Ki} \times \mathrm{Wi})+(\mathrm{Ke} \times \mathrm{We})(3) \\
& \mathrm{Ke}=[\mathrm{Rf}+\beta \times(\mathrm{Rm}-\mathrm{Rf})+\alpha b r(4)
\end{aligned}
$$

A organização na qual foi desenvolvido o estudo de caso foi a Gerdau S.A. Na sequência apresentar-se-á a análise dos dados da pesquisa.

\section{Análise dos resultados}

\section{Dados e análise da pesquisa}

Com base nas demonstrações financeiras da empresa Gerdau S.A. remetidas à CVM, NYSE e SEC, foram calculados os indicadores de desempenho, como pode ser observado na Tabela 1.

\begin{tabular}{|c|c|c|c|}
\hline Indicadores & BR GAAP & US GAAP & IFRS \\
\hline Relação capital de terceiros/capital próprio & $111,5 \%$ & $112,6 \%$ & $122,7 \%$ \\
\hline Relação capital de terceiros / passivo total & $52,7 \%$ & $52,9 \%$ & $55,1 \%$ \\
\hline Imobilização de recursos permanentes & $60,1 \%$ & $56,7 \%$ & $56,8 \%$ \\
\hline Liquidez geral & 1,08 & 1,04 & 1,02 \\
\hline Liquidez corrente & 2,56 & 2,42 & 2,44 \\
\hline Retorno sobre o investimento & $10,7 \%$ & $10,4 \%$ & $13,5 \%$ \\
\hline Retorno sobre o patrimônio líquido & $25,2 \%$ & $30,7 \%$ & $27,6 \%$ \\
\hline Valor econômico agregado & $\mathrm{R} \$ 783.649$ & $\mathrm{R} \$ 822.848$ & $\mathrm{R} \$ 1.804 .146$ \\
\hline Market value added & $\mathrm{R} \$ 9.919 .616$ & $\mathrm{R} \$ 10.562 .735$ & $\mathrm{R} \$ 21.854 .484$ \\
\hline
\end{tabular}

Tabela 1

Indicadores de desempenho e de geração de valor 
Os resultados evidenciam que os indicadores de desempenho calculados com base em BR GAAP apresentam números inferiores para a maior parte dos indicadores calculados em US GAAP e IFRS. Essa tendência se confirma também no cálculo do EVA e do MVA, os quais apresentam valores crescentes em BR GAAP, US GAAP e IFRS respectivamente.

Pelo BR GAAP a empresa apresenta uma relação de CT/PL de 111,5\% e imobiliza 60,1\% de seus recursos não correntes. Em US GAAP esses indicadores foram de 112,6\% e 56,7\%, e em IFRS de 122,7 e $56,8 \%$.

Nos indicadores de endividamento, os resultados em BR GAAP e US GAAP apresentaram-se inferiores aos indicadores calculados em IFRS. Esse fato justifica-se pela proporção maior de capital de terceiros e menor de patrimônio líquido na estrutura financeira da empresa, nas demonstrações em IFRS, comparadas aos números nas demonstrações em BR GAAP.

$\mathrm{O}$ volume maior de capital de terceiros deve-se principalmente às contas de imposto de renda/contribuição social diferidos, e opções por compra de ações, as quais compõem o passivo não-circulante. De acordo com o IFRS, os efeitos do imposto de renda devem ser refletidos nas demonstrações financeiras consolidadas nos mesmos períodos em que os ativos e passivos que geram tais efeitos forem contabilizados. As diferenças entre as bases contábil (apresentadas nas posições contábeis) e fiscal (montante que será dedutível ou tributável para fins de imposto de renda) dos ativos e passivos são classificadas como diferenças temporárias. O imposto de renda diferido ativo só deve ser inicialmente reconhecido se houver probabilidade de que seja realizado contra ganhos tributáveis a serem gerados no futuro. Os ativos e passivos fiscais diferidos devem sempre ser classificados como não correntes, e não devem ser descontados. Já de acordo com o BR GAAP, são reconhecidos impostos diferidos passivos sobre diferenças temporárias, exceto quando correspondem a diferenças de valores de ativos não destinados à venda. Os ativos e passivos fiscais diferidos devem ser classificados como correntes ou não-correntes em função de sua expectativa de realização.

Já na conta opções de vendas de ações, a companhia realizou instrumentos financeiros relativos a algumas das aquisições, que envolvem compromissos na aquisição de ações de acionistas minoritários das empresas adquiridas, ou concedeu opções de venda a alguns acionistas minoritários para venderem suas ações à companhia. Esses instrumentos financeiros derivativos estão registrados no balanço patrimonial da companhia na conta opções por compra 
de ações, e a determinação desse valor envolve uma série de estimativas que podem ter impacto significativo no resultado final do cálculo.

De acordo com o BRGAAP, essas operações são registradas por seus valores de custo, acrescidas dos rendimentos obtidos até a data das demonstrações financeiras, conforme as taxas acordadas com as instituições financeiras, e não superam o valor de mercado. Tal critério difere da valorização por valor justo. Uma alteração na legislação societária brasileira equiparou o tratamento contábil em BRGAAP com a norma IFRS a partir de 2008.

Em BR GAAP os indicadores de liquidez apresentam capacidade de pagamento a longo e curto prazo, conforme os índices de liquidez geral e corrente de 1,08 e 2,56, respectivamente. US GAAP e IFRS apresentaram os índices de liquidez geral de 1,04 e 1,02 e liquidez corrente de 2,42 e 2,44 respectivamente.

Verifica-se que não houve diferenças significativas nos indicadores de liquidez. Isso deve-se ao fato de que as principais alterações no balanço patrimonial concentraram-se nas contas não circulantes.

Em relação à rentabilidade, verificou-se uma diferença relevante no ROI e ROE. Em BR GAAP e US GAAP, o ROI foi de 10,7\% e 10,4\% respectivamente. Em IFRS esse indicador totalizou 13,5\%. A diferença deve-se a uma variação em maior proporção do lucro em relação ao ativo total no momento da conciliação entre as normas. O ajuste no LL foi de $22 \%$, enquanto no ativo total o ajuste foi de $17 \%$.

Em relação ao aumento de $22 \%$ no LL, $43 \%$ desse total refere-se ao ajuste na parcela dos minoritários na alteração do critério de consolidação; $16 \%$ ao ajuste de opção de compra e/ou venda de ações e $35 \%$ à reclassificação do efeito de conversão para moeda estrangeira.

Em relação ao ajuste dos minoritários na alteração do critério de consolidação, em IFRS o investidor deve contabilizar seu investimento considerando o tipo de joint venture. A Gerdau utilizou a equivalência patrimonial como política para as joint venture, utilizando o conceito de controladora para fins de consolidação integral.

Já em BR GAAP as entidades com controle compartilhado devem ser consolidadas proporcionalmente. Os componentes do ativo e passivo, as receitas, os gastos da sociedade com controle compartilhado são somados às posições contábeis consolidadas, na proporção da participação do investidor em seu capital social.

Quanto às alterações referentes à reclassificação do efeito de conversão para moeda estrangeira, em IFRS a variação percentual da taxa de câmbio sobre os investimentos no exterior, bem como sobre o saldo do PL das empresas controladas com moeda funcional diferente da 
moeda funcional da empresa controladora, foi reconhecida diretamente no PL, em uma conta específica.

Em BR GAAP essa variação foi reconhecida no resultado do exercício na linha de equivalência patrimonial, devido à Lei 11.638/07, que equiparou o tratamento contábil das demonstrações financeiras em BR GAAP com IFRS em 2008.

A variação percebida na conciliação de BR GAAP para IFRS, no ativo total, foi de R\$ 4.666.713. Desse montante, $78 \%$ são devidos aos ajustes nas contas do ativo não circulante, dos quais $47 \%$ referem-se ao imobilizado e $10 \%$ à equivalência patrimonial.

A principal diferença do imobilizado entre as demonstrações em BR GAAP e IFRS está na combinação dos negócios em relação ao método de compra. Em IFRS, a entidade compradora deve alocar, na data da combinação, o custo de aquisição incluindo os custos diretos com a transação, reconhecendo contabilmente os ativos adquiridos identificados e os passivos e passivos contingentes assumidos, valorizados pelo valor justo.

Já em BR GAAP, o enfoque do valor justo não é utilizado. O ágio ou deságio é calculado pela diferença simples entre o valor de aquisição e o patrimônio líquido da entidade adquirida.

O ativo circulante representou $22 \%$ da variação do ativo total. Dessa forma, percebe-se que o maior impacto está nas contas do ativo não circulante.

Será dada ênfase na análise quanto à diferenciação entre BR GAAP e IFRS, visto que os motivos que diferenciam as demonstrações elaboradas em BR GAAP e US GAAP das elaboradas em IRFS são substancialmente semelhantes.

Quanto à geração de valor nos cálculos do EVA e MVA, os valores apresentados foram crescentes. Os valores do EVA foram $\mathrm{R} \$ 783.649$, $\mathrm{R} \$ 822.848$ e $\mathrm{R} \$ 1.804 .146$, e do MVA R\$ 9.919.616, R\$ 10.562.735 e R \$ 21.854.484, em BR GAAP, US GAAP e IFRS respectivamente.

O principal impacto percebido no cálculo do EVA, em relação aos ajustes das demonstrações financeiras, encontra-se principalmente nas contas do ativo não circulante, principalmente nas contas de imobilizado e equivalência patrimonial.

Como não houve variação no CMPC, o ROI e consequentemente o EVA, calculados pelas demonstrações financeiras em IFRS, são maiores do que em BR GAAP, o que é justificado pelos ajustes de $22 \%$ no LL e de $17 \%$ no ativo total.

Percebe-se, pelas análises, que diferentes práticas contábeis podem levar a interpretações distintas, tanto da situação econômico-financeira da empresa como de seu valor de mercado. As causas dessas diferenças podem vir da natureza da propriedade empresarial e as formas de financiamento; da tributação; do nível de educação na área contábil; do estágio de desenvolvimento econômico de cada país; do sistema legal e político; da cultura e religião. Nesse 
contexto, a adoção das IFRS será fundamental para proporcionar critérios de comparabilidade e transparência entre empresas de diferentes países, buscando disponibilizar informações financeiras de melhor qualidade para acionistas e autoridades responsáveis.

\section{Conclusão}

Os objetivos propostos neste estudo foram comparar os dados evidenciados segundo as normas contábeis brasileiras, americanas e internacionais, apoiado em uma análise de indicadores de desempenho e de geração de valor calculados a partir das demonstrações financeiras preparadas com base nessas diferentes normas pela empresa Gerdau S.A. Os resultados evidenciam que os indicadores econômico-financeiros calculados com base em BR GAAP apresentam números inferiores para a maior parte dos indicadores calculados em US GAAP e IFRS. Essa tendência se confirma também no cálculo do EVA e do MVA, os quais apresentam valores crescentes em BR GAAP, US GAAP e IFRS respectivamente.

Isso confirma Bernardi, Costa e Ikeda (2002) ao comentarem que, como resultado da utilização de diferentes normas, seria possível obter informações contábeis diferenciadas para uma mesma organização, dependendo do padrão contábil empregado.

Dessa forma, acredita-se que as diferenças encontradas com uso das diferentes normas podem impactar o processo de tomada de decisão da empresa quanto à sua estrutura de capital, políticas de investimento e financiamento e remuneração dos acionistas, as quais tomam por base as demonstrações financeiras.

O resultado da pesquisa foi limitado ao conteúdo das demonstrações financeiras publicadas pela Gerdau S.A. em BR GAAP, US GAAP e IFRS referentes ao exercício de 2006, visto que esse período era o único disponível até o momento da pesquisa. O método utilizado foi o estudo de caso. Como se trata de uma investigação empírica que pesquisa fenômenos dentro de um contexto real onde o pesquisador não tem controle sobre eventos e variáveis, o estudo de caso não permite que as conclusões sejam generalizadas.

Dessa forma, estudos adicionais são necessários para identificar as causas da não similaridade entre os resultados alcançados com o uso das diferentes normas.

\section{Referências}

ASSAF NETO, Alexandre. Estrutura e análise de balanços: um enfoque econômico financeiro. 8. ed. São Paulo: Atlas, 2007.

ASSAF NETO, Alexandre. Finanças corporativas e valor. São Paulo: Atlas, 2007. 
BERNARDI, André Gaeta; COSTA, Fábio Moraes da; IKEDA, Ricardo Hirata. Principais diferenças entre UK GAAP e US GAAP: um estudo de caso da AstraZeneca. In: CONGRESSO USP DE CONTROLADORIA E CONTABILIDADE, 2., 2002, São Paulo. Anais... São Paulo: FEA/USP, 2002. CD Rom.

BEUREN, Ilse Maria (Org.). Como elaborar trabalhos monográficos em contabilidade. São Paulo: Atlas, 2003.

COPELAND, Tom; KOLLER, Tim; MURRIN, Jack. Avaliação de empresas: valuation. São Paulo: Makron Books, 2000.

EHRBAR, Al; STEWART, Stern. EVA: valor econômico agregado: a verdadeira chave para a criação de riqueza. Tradução Bazán Tecnologia e Linguística. 2. ed. Rio de Janeiro: Qualitymark, 2003.

GIL, A. C. Como elaborar projetos de pesquisa. São Paulo: Atlas, 2002.

HENDRIKSEN, Eldon S.; VAN BREDA, Michel F. Teoria da contabilidade. 5. ed. Tradução Antonio Zoratto Sanvicente. São Paulo: Atlas, 1999.

LINHARES, Robson de Souza. A nova estrutura do balanço patrimonial proposta na reformulação da Lei 6.404/76 e seus reflexos sobre os indicadores econômicos e financeiros dele extraídos. In: ENCONTRO NORDESTINO DE CONTABILIDADE, 11, 2003, Fortaleza. Anais... 11 a 13 mai. 2003. Disponível em: <http://www.fucape.br/producao_ cientifica.asp?secao=result\&id_tipo=2\&ano=2003\&pagina=4>. Acesso em: 1 abr. 2008.

MARTINS, Gilberto de Andrade; THEÓPHILO, Carlos Renato. Metodologia da investigação científica para ciências sociais aplicadas. São Paulo: Atlas, 2007.

MATARAZZO, Dante Carmine. Análise financeira de balanços. 6. ed. São Paulo: Atlas, 2007.

NIYAMA, Jorge K. Contabilidade internacional. São Paulo: Atlas, 2005.

PRICEWATERHOUSECOOPERS (PWC). Semelhanças e diferenças IFRS $\mathbf{x}$ USGAAP $\mathbf{x}$ práticas contábeis adotadas no Brasil. Disponível em: <http://www.pwc.com.br> Acesso em: 23 abr. 2007.

REIS, Arnaldo Carlos de Rezende. Demonstrações contábeis: estrutura e análise. São Paulo: Saraiva, 2003.

RICCI, Michele A. D. As implicações práticas do uso de diferentes padrões contábeis e o impacto quanto à gestão do crédito para exportação. In: CONGRESSO USP DE CONTROLADORIA E CONTABILIDADE, 3., 2003, São Paulo. Anais... São Paulo: FEA/USP, 2003. CD Rom.

STEWART III, G. Bennett. The quest for value: a guide for senior managers. HarperBusiness, New York, 1991.

WEFFORT, Elionor F. J. O Brasil e a harmonização contábil internacional: influências dos sistemas jurídico e educacional, da cultura e do mercado. São Paulo: Atlas, 2005. 
YIN, R. K. Estudo de caso: planejamento e métodos. Porto Alegre: Bookman, 2005. 